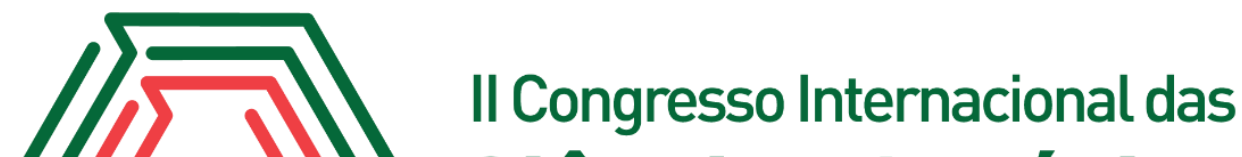 Ciências Agrárias COINTER - PDVAgro 2017
}

\section{INFLUÊNCIA DA COLORAÇÃO DA EMBALAGEM NA VIABILIDADE DE SEMENTES \\ ORGÂNICAS DE Solanum lycopersicum var. cerasiforme DURANTE O ARMAZENAMENTO}

\author{
Apresentação: Pôster
}

Abraão Rodrigues de Almeida ${ }^{1}$; Alciele da Silva Leite ${ }^{2}$; Jane Clésia Silva dos Santos ${ }^{3}$; Laís Pereira da Silva ${ }^{4}$; Pablo Radamés Cabral de França ${ }^{5}$

\section{Introdução}

O tomateiro (Solanum lycopersicum) é uma cultura de relevante importância no setor alimentício devido seu uso numa grande diversidade de alimentos, cujo consumo pode ser in natura, como em saladas ou na forma de extrato, onde é muito empregada nas indústrias de molho.

De acordo com TONEL (2010) o processo de estocagem de sementes compõe uma das etapas mais importantes no sistema de produção, devido a todo o investimento humano e material gastos durante a produção pode resultar em perda, caso as condições seja inadequadas. Corroborando a isso, ha relatos de agricultores quanto à redução da viabilidade das sementes quando são acondicionadas em garrafas tipo PET de cores diferentes, obtendo resultados divergentes para cada cultura.

Dessa forma, objetivou-se com esse trabalho avaliar a qualidade fisiológica de sementes de tomate cereja (Solanum lycopersicum var. cerasiforme), submetidas ao acondicionamento em garrafas tipo PET com colorações diferentes, sob dois ambientes de armazenamento.

\section{Fundamentação Teórica}

Segundo Carvalho \& Nakagawa (2012) há muitos elementos que influenciam na preservação e manutenção da qualidade das sementes no processo de estocagem, sob determinadas condições ambientais, entre eles tem o tipo de embalagem que são usadas. As embalagens podem

\footnotetext{
${ }^{1}$ Bacharelando em Agronomia, IFPE, abraaoalmeida98@ gmail.com

${ }^{2}$ Bacharelando em Agronomia, IFPE, alcieleleite@gmail.com

${ }^{3}$ Bacharelando em Agronomia, IFPE, janeclsia@gmail.com

${ }^{4}$ Bacharelando em Agronomia, IFPE, laispereira537@ gmail.com

${ }^{5}$ Eng. Agrônomo. Prof. Dr, IFPA, pabloradames@hotmail.com
} 
ser divididas em relação à troca de vapor de água sendo elas: permeáveis, semi-permeáveis e impermeáveis, a troca de umidade pode ocorrer entre as sementes e o ambiente onde estão inseridas (Baudet, 2003).

O tipo de embalagem utilizada no acondicionamento das sementes durante o armazenamento somadas à temperatura e a umidade relativa do ar assumem relevante importância na preservação da sua viabilidade e, principalmente, do vigor (CROCHEMORE,1993; KUNN et al., 2012).

\section{Metodologia}

O trabalho foi realizado no Laboratório de Análise de Sementes do Instituto Federal de Pernambuco (IFPE) Campus Vitória de Santo Antão-PE. Utilizaram-se sementes orgânicas de tomate cereja (S. lycopersicum var. cerasiforme) obtidas no município de Lagoa Seca - PB.

A pesquisa foi de natureza quantitativa, sendo o delineamento experimental inteiramente casualizado, com quatro repetições, em analise fatorial $3 \times 2 \times 2$, envolvendo três período de armazenamento ( 0, 3, 6 meses), 2 tipos de embalagens (PET transparente e PET Verde) e dois ambientes (natural e geladeira). Para a avaliação da qualidade fisiológica das sementes, foram realizados os seguintes testes:

Teor de água: utilizando-se quatro repetições para cada tratamento, sendo colocadas em recipientes metálicos, pesadas antes e após serem submetidas à estufa com $105 \pm 3{ }^{\circ} \mathrm{C}$ por 24 horas.

Germinação: realizado em quatro repetições de 50 sementes colocadas em caixas gerbox, sobre duas folhas de papel mata borrão umedecidas com 2,5 vezes o peso do substrato, seguindo os procedimentos de acordo com Brasil (2009) e levados aos germinadores tipo Biochemical Oxigen Demand (B.O.D.) regulado à temperatura constante de $25^{\circ} \mathrm{C}$. As avaliações foram efetuadas diariamente após a semeadura, do $4^{\circ}$ ao $11^{\circ}$ dia, considerando-se germinadas as sementes que emitiram a raiz primária e a parte aérea.

Primeira Contagem de Germinação (\%): realizada no quarto dia após o início do teste, conduzido conjuntamente com o teste de germinação.

Índice de velocidade de germinação (IVG): realizado em conjunto ao teste de germinação, através de contagens diárias das plântulas do $4^{\circ}$ até o $11^{\circ}$ dia após a semeadura. sendo o índice calculado pela fórmula proposta por Maguire (1962). 
Foi utilizada a planilha eletrônica Microsoft Excel para formatação dos dados e confecção de gráficos. Para as análises estatísticas foi empregado o programa computacional ASSISTAT versão 7.7 beta - 2016 .

\section{Resultados e Discussões}

Em relação aos teores médios de água (Figura 1), as sementes armazenadas em ambiente natural e de geladeira, obtiveram um aumento no teor ao longo do armazenamento, sendo mais acentuado no ambiente natural, devido não houver controle da temperatura e umidade. Quanto às embalagens, também ocorre esse pequeno aumento, levando em consideração que as garrafas tipo PET são impermeáveis, mas caso não tenha havido uma boa vedação na tampa da garrafa, a troca de umidade é inevitável, cujo fato é ocasionado quando se usa esse tipo de embalagem.

A

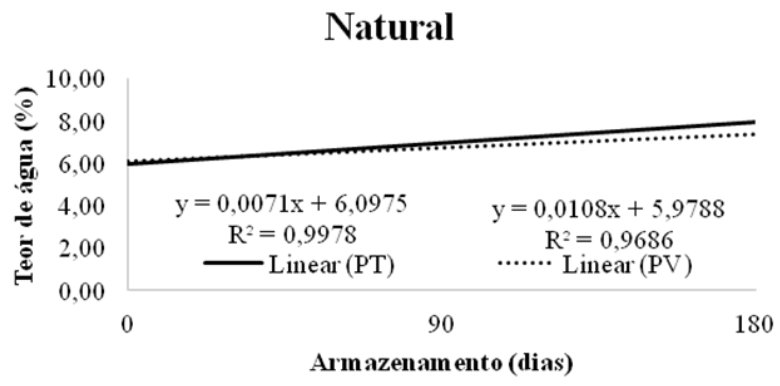

B

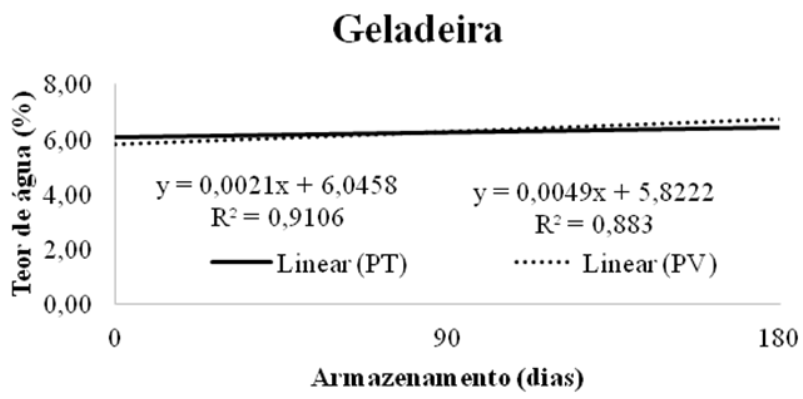

Figura 1. Teor de água (\%) de sementes de S. lycopersicum acondicionadas em garrafas tipo PET com cores diferentes, armazenadas em ambiente Natural (A) e de Geladeira (B). PT = PET transparente; PV = PET cor verde.

Quanto à germinação (Figura 2), as sementes de tomate armazenadas em garrafa pet verde e garrafa pet transparentem submetida a ambiente natural e de geladeira, não apresentaram redução na germinação durante todo o período de armazenamento. Dessa forma, ambas as embalagens são eficientes na manutenção da germinação durante 180 dias em ambiente natural e de geladeira. Pesquisas feitas por SILVA (2010) coincidem com os resultados obtidos, comprovando a viabilidade das sementes de diferentes culturas em embalagens impermeáveis. 
A

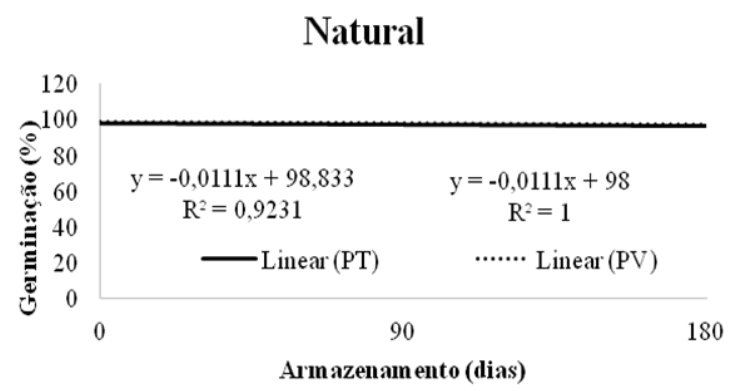

B

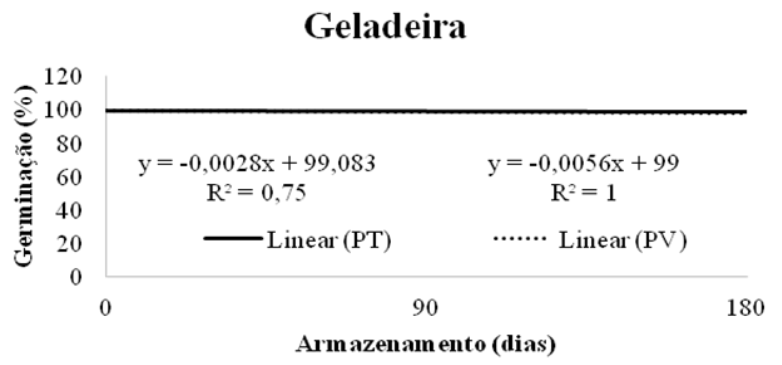

Figura 2. Germinação (\%) de sementes de S. lycopersicum acondicionadas em garrafas tipo PET com cores diferentes, armazenadas em ambiente Natural (A) e de Geladeira (B). PT = PET transparente; PV = PET cor verde.

Os resultados da primeira contagem (Figura 3) indicaram que as amostras, tanto em garrafa pet como em ambiente natural nos dois tipos de ambientes, apresentaram um decréscimo de porcentagem de plântulas normais aos 90 e 180 dias comparado ao período inicial. Havendo maior redução quando as sementes foram armazenadas em ambiente natural.

A

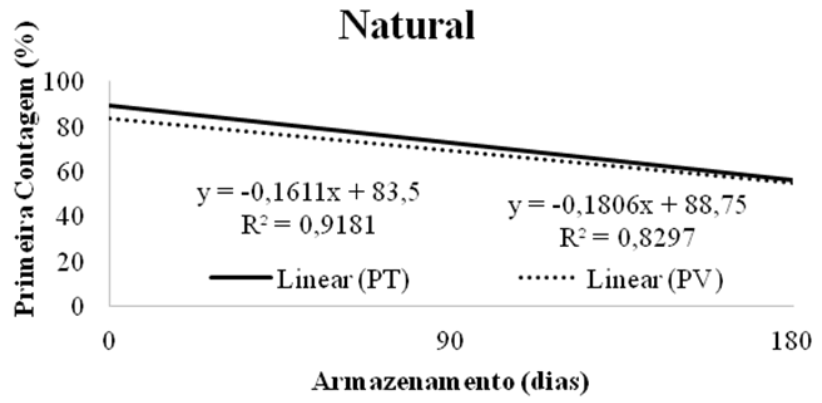

B

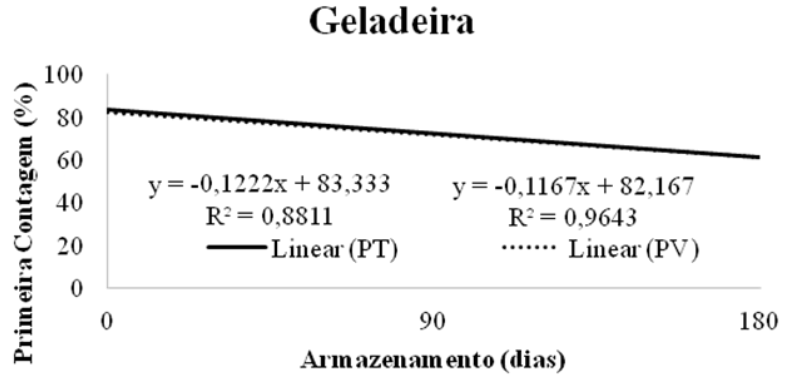

Figura 3. Primeira contagem (\%) de sementes de S. lycopersicum acondicionadas em garrafas tipo PET com cores diferentes, armazenadas em ambiente Natural (A) e de Geladeira (B). PT = PET transparente; PV = PET cor verde.

Quando se verificou os valores médios do índice de velocidade de germinação (IVG) (Figura 4), constatou-se comportamento similar entre as embalagens testadas, as quais obtiveram um decréscimo linear ao longo do armazenamento, sendo mais acentuado no ambiente natural. 
A

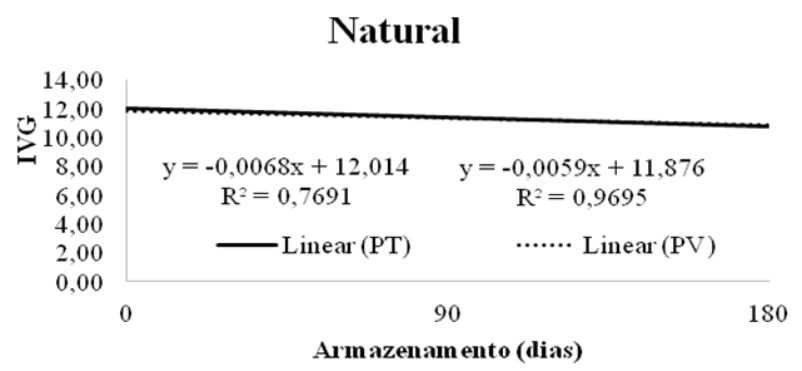

B

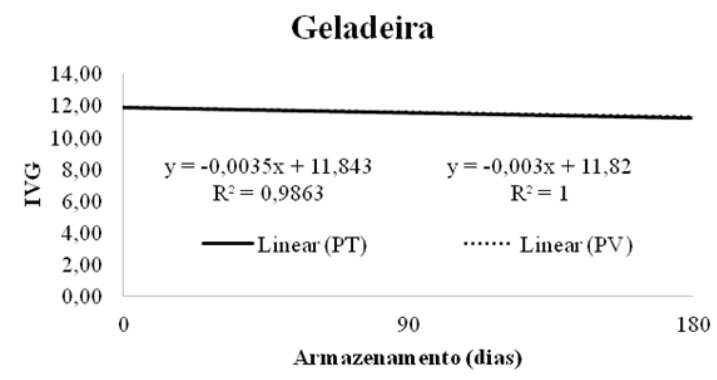

Figura 4. IVG (\%) de sementes de S. lycopersicum acondicionadas em garrafas tipo PET com cores diferentes, armazenadas em ambiente Natural (A) e de Geladeira (B). PT = PET transparente; PV = PET cor verde.

\section{Conclusões}

Conclui-se que as sementes de S. lycopersicum var. cerasiforme acondicionadas em garrafa PET verde e garrafa PET transparente não apresentam diferença na manutenção da viabilidade ao longo dos 180 dias de armazenamento.

Quanto ao ambiente de armazenamento, as sementes de S. lycopersicum var. cerasiforme quando mantidas em geladeira, obtiveram maior viabilidade da qualidade fisiológica durante os 180 dias em comparação ao ambiente natural.

\section{Referências}

BAUDET, L.M.L. Armazenamento de sementes. In: PESKE, ST.; ROSENTAL, M.D.; ROTA, G.R.(ed.). Sementes: fundamentos científico e tecnológico, pelotas: Ed. Universitária- UFPel, 2003. P.370-418.

BRASIL, Ministério da Agricultura e Reforma Agrária. Regras para Análise de sementes. Brasília: SNDP/DNDV/CLAV, 2009. 395p.

CARVAlHO, N. M. de; NAKAGAWA, J. Sementes: ciência, tecnologia e produção. 5. ed. Jaboticabal: FUNEP, 2012. 590 p.

CROCHEMORE, M. L. Conservação de sementes de tremoço azul em diferentes embalagens. Revista Brasileira de Sementes, Londrina, v.15, n.2, p.227-232, 1993.

KUNN, P. R.; KULCZYNSKI, S. M.; ROSA, L. G.; FROZZA, R. A.; ZANCHET, B. M. Influência do tipo de embalagem na qualidade fisiológica de sementes de tomateiro, durante a comercialização. Enciclopédia biosfera, Centro Científico Conhecer, Goiânia, p. 647, 2012.

MAGUIRE, J. D. Speed of germination-aid in selection and evaluation for seedlig emergence and vigor. Crop Science, v. 2, p. 176-177, 1962.

SILVA, F. S.; PORTO, A. G.; PASCUALI, L. C.; SILVA F. T. C. Viabilidade do armazenamento de sementes em diferentes embalagens para pequenas propriedades rurais. Revista de Ciências Agro-Ambientais, Alta Floresta, v.8, n.1, p.45- 56, 2010.

TONEL, F. R. ; SILVA, A. C. S.; MORAES, D. M. Avaliação da qualidade fisiológica de lotes de sementes de melão após armazenamento. XIX CIC, II mostra científica, 2010. 